\title{
O TERCEIRO SETOR NO MUNDO JURÍDICO: A IMPORTÂNCIA DO VOLUNTARIADO E RESPONSABILIDADE SOCIAL
}

THE THIRD SECTOR IN THE LEGAL WORLD: THE IMPORTANCE OF VOLUNTEER AND SO-

CIAL RESPONSIBILITY

Glauber Camacho Gimenez GARCIA ${ }^{1}$

Raysa CONTE ${ }^{2}$

ISSUE DOI: $10.21207 / 1983.4225 .859$

\section{RESUMO}

O Terceiro Setor, nas últimas décadas, vem se desenvolvendo vertiginosamente, carecendo de regulação própria que abranja todos os seus aspectos em um texto legal claro, abolindo a vasta legislação esparsa acerca do tema. Neste sentido, a questão do Terceiro Setor, voluntariado e exercício da responsabilidade social deve ser analisada também sob o prisma jurídico, o que somente há pouco tempo vem se tornando objeto de estudo do Direito.

Palavras-chaves: legalidade, empresa, sociedade.

\section{ABSTRACT}

The Third Sector, in recent decades, has been developing dramatically, lacking its own regulation that covers all its aspects in a clear legal text, abolishing the vast sparse legislation on the subject. In this 
sense, the issue of the Third Sector, volunteering and the exercise of social responsibility must also be analyzed from the legal point of view, which has only recently been the subject of law studies.

Keywords: legality, company, society.

\section{INTRODUÇÃO}

Diferente de filantropia ou de função social a responsabilidade social é a consciência da empresa em relação à sua importância na sociedade, que se transformou em um diferencial competitivo, de forma a elaborar e executar projetos que tenham impacto positivo na sociedade, como por exemplo, projetos de inserção das minorias e que incluam o meio ambiente.

Ethos, é:

Na definição de Oded Grajew (2001), presidente do Instituto

(...) a atitude ética da empresa em todas as suas atividades. Diz respeito às interações da empresa com funcionários, fornecedores, clientes, acionistas, governo, concorrentes, meio ambiente e comunidade. Os preceitos da responsabilidade social podem balizar, inclusive, todas as atividades políticas empresariais. (GRAJEW, Instituto Ethos, 2001).

Essa nova inclinação das empresas faz parte do chamado terceiro setor, juntamente com vários outros tipos de entidades como organizações e associações e sua expansão se deve essencialmente ao déficit na prestação de serviços do primeiro setor, qual seja o Estado, que acaba por "terceirizar" as funções que lhe compete, como saúde, educação, etc. Para Carlos Montaño (2003) na verdade o que o Terceiro Setor origina é a inversão dos direitos do cidadão em programas assistencialistas, em trajes de solidariedade imposta e desenvolvida pelo Estado.

\subsection{SIGNIFICADO DA RESPONSABILIDADE SOCIAL}

De acordo com o Instituto Ethos:

(...) a questão da responsabilidade social vai, portanto, além da postura legal da empresa, da prática filantrópica ou do apoio à comunidade. Significa mudança de atitude, numa perspectiva de gestão empresarial com foco na qualidade das relações e na geração de valor para todos. 
Isso permite duas possibilidades de interpretação: que as políticas públicas do Estado não são totalmente eficientes ou que ao tomar para si a responsabilidade social, a iniciativa privada desbanca o poder público diante da população.

Moreira, Mattiuz e Souza (2004) afirmam que:

Só é possível que uma empresa exerça plenamente sua responsabilidade social empresarial, quando possui uma gestão eficaz de suas partes interessadas, tanto com relação ao seu público interno (beneficiários internos), quanto ao externo (beneficiários externos). (MOREIRA, MATTIUZ e SOUZA, 2004, p.6)

Dessa forma, é possível compreender que não basta que uma empresa aja dentro das leis trabalhistas, mas que também harmonize seus objetivos somados aos de seus colaboradores, de modo a otimizar a relação entre ambos e consequentemente alcançar um reflexo positivo em suas atividades sociais.

De acordo com Moreira, Mattiuz e Souza (2004, p.7): "Na empresa, a responsabilidade social com seu público interno possibilita a criação de um ambiente de trabalho sustentável, que resulta em maior produtividade, comprometimento e motivação."

\subsubsection{DESENVOLVIMENTO HISTÓRICO DA RESPONSABILIDADE SOCIAL}

Mundialmente falando a responsabilidade social surgiu nos Estados Unidos no final do século XIX, tendo como seu precursor Andrew Carnegie, através do livro "O Evangelho da Riqueza", pautado nos princípios de caridade e custódia. Aproximadamente na metade do século seguinte esses princípios já eram bem difundidos entre as empresas americanas e mesmo as que não aceitavam tais princípios perceberam que seriam forçadas para tanto pelo Estado.

Nesta época surge um novo conceito para o tema, contrário ao anterior, proposto por Howard Bowen, em que afirmava ser a responsabilidade social um dever moral de "implementar as políticas, tomar as decisões ou seguir as linhas de ação que sejam desejáveis em torno dos objetivos e dos valores de nossa sociedade" (Bowen citado em Stoner e Freeman, 1985, p.73). O autor ainda dizia que os negócios significavam poder e por consequência atingiam a vida da população de alguma maneira, esta por 
sua vez esperava alguma responsabilidade como uma feedback o que acabou sendo uma aliada à estratégia daquelas.

Posteriormente a evolução do conceito permitiu o entendimento de que as necessidades da sociedade já não cabiam mais às empresas que deveriam somente cuidar do interesse de seus acionistas, Milton Friedman, um de seus principais precursores, justificou da seguinte maneira:

Há uma, e apenas uma, responsabilidade social das empresas: usar seus recursos e sua energia em atividades destinadas a aumentar seus lucros, contanto que obedeçam as regras do jogo (...) [e] participem de uma competição aberta e livre, sem enganos e fraudes (...). (FRIEDMAN citado em STONER e FREEMAN, 1985, p.73).

A partir da década de 70, Carrol, outro autor sobre o tema aponta nova visualização do tema no contexto da época:

\footnotetext{
Os negócios estão sendo chamados para assumir responsabilidades amplas para a sociedade como nunca antes e para servir a ampla variação de valores humanos (qualidade de vida além de quantidade de produtos e serviços). Os negócios existem para servir a sociedade; seu futuro dependerá da qualidade da gestão em responder as mudanças de expectativas do público. (Carrol, 1999, p.282)
}

Ao final da mesma década este mesmo autor indica um significado mais abrangente para a responsabilidade social, fragmentando o conceito em quatro tipos, quais sejam: responsabilidade econômica: produzir aquilo que a sociedade necessita para obtenção de lucro, movimentando a máquina do capitalismo; responsabilidade legal: é realizar seu trabalho em conformidade com a lei de modo a proporcionar segurança e respeito ao meio ambiente; responsabilidade ética: ter postura ética diante de suas atividades; responsabilidade discricionária: planejamento das empresas de aplicar suas ações voluntárias onde não se nota tal necessidade são direcionadas de acordo com a vontade de seus dirigentes e podem ser encaradas como estratégia.

A partir daí tal conceito e o estudo do mesmo se espalharam pelo mundo, não só no meio empresarial, chegando, no final da década de 90, a ser sistematizados alguns princípios direcionadores pela Organização das Nações Unidas (ONU).

\subsubsection{SURGIMENTO NO BRASIL}


É a partir da década de 60 que o tema começa a ser trazido para o Brasil, inicialmente com a Associação dos Dirigentes Cristãos de Empresas (ADCE).

Mas foi somente a partir da década de 90 que o tema ganhou força com empresas que aderiram à causa, atividades das organizações não governamentais e também institutos de pesquisa. $\mathrm{O}$ sociólogo Herbert de Souza (Betinho) foi um dos principais difusores acerca do tema, a frente do Instituto Brasileiro de Análises Sociais e Econômicas (IBASE).

Ao longo da década muito se discutiu sobre responsabilidade social, por meio de seminários e conferências com o objetivo de que o maior número de empresas aderisse ao tema. Inúmeras campanhas foram lançadas, medidas foram tomadas e ações postas em práticas pelas grandes corporações.

Em 97 o IBASE lança uma campanha propondo às grandes empresas que divulgassem o balanço social de suas ações, que era um documento com informações das atividades desenvolvidas pelas empresas à seus colaboradores ou à sociedade divulgado anualmente e oferecia o "Selo do Balanço Social" como estímulo ao modelo proposto, o que conferia uma visualização positiva frente à sociedade.

É no final desta década que nasce o "Instituto Ethos de Empresas e Responsabilidade Social", fundado pelo empresário israelense Oded Grajew, hoje ícone quando se trata de responsabilidade social e voluntariado no Brasil. Referido instituto tem como propósito "auxiliar as empresas a assimilar o conceito de responsabilidade social empresarial e incorporá-lo ao dia-a-dia de sua gestão, num processo contínuo de avaliação e aperfeiçoamento."

Já a partir do ano 2000 o mesmo instituo criou indicadores de forma a avaliar o nível de responsabilidade social das empresas e anualmente promove a Conferência Nacional de Empresas e Responsabilidade Social, que a cada ano vem tendo maior número de empresas participantes e discute temas diferentes.

\subsubsection{DA DEDUÇÃO FISCAL}

Outra questão é o estímulo fiscal fornecido pelo governo às empresas engajadas nas questões sociais. Apesar de pertencer primeiramente ao Estado o provimento das políticas públicas, a partir da evolução do modelo capitalista, descobriu-se que é um ótimo negócio investir no social. 
Deste modo, no Brasil, há um grande incentivo às empresas consideradas "cidadãs", garantido por leis federais, através da diminuição fiscal oferecidas àquelas empresas que doam ou patrocinam projetos culturais.

Por exemplo, Lei n ${ }^{\circ} 11.770$, de 9 de setembro de 2008, "que cria o Programa Empresa Cidadã, destinado à prorrogação da licença-maternidade, no tocante às empregadas de pessoas jurídicas" e o decreto $\mathrm{n}^{\mathrm{o}}$. 7.052/2009 que regulamenta referida lei.

A importância da responsabilidade social pode ser entendida através das lentes da "estratégia empreendedora", ou seja, um diferencial competitivo, de modo que aumenta sua renda e permite uma expansão no seu desenvolvimento uma vez que provoca uma conscientização maior no consumidor ao procurar produtos ou serviços provindos de empresas "conscientes" e que "zelem" por um futuro sustentável.

As empresas do século XXI já não parecem totalmente fascinadas no lucro, mas também passaram a se preocupar com os recursos naturais que são matérias-primas e somados a mão-de-obra competente proporcionam a estas o produto ou serviço, de modo que sem essa preocupação com o início da cadeia percebe-se que se tem chegado ao ponto fraco, questão primordial de uma empresa.

Essa visão social das corporações não parece um modismo, mas uma verdadeira mudança na postura, comprometimento e visão estratégica em relação à sociedade a qual está inserida. Como consequência há também uma mudança na postura do consumidor, com informação ele se torna mais exigente e consciente na hora de comprar e acaba favorecendo a "empresa cidadã".

Vale ressaltar a importância que traz a responsabilidade social ao aperfeiçoar, reavivar e instituir novos programas sociais somados ao benefício proporcionado à sociedade através das ações prestadas pelas empresas nas áreas de saúde, educação, economia, meio ambiente, transporte, atividades de lazer e socioculturais, etc.

\subsubsection{CONSEQUÊNCIAS DA RESPONSABILIDADE SOCIAL}

Essencialmente as principais consequências para as empresas que vestem a camisa da responsabilidade social, são relacionadas à sua imagem 
diante do consumidor. Ao desenvolver projetos sociais as corporações ganham, por exemplo, credibilidade, confiança e valorização da sociedade, elementos que indiretamente levam ao maior lucro.

Emerson Kapaz, do Instituto Ethos, ao ser perguntado o que empresas que praticam a responsabilidade social podem ganhar, confirma: "A confiança do consumidor e a percepção da sociedade de que aquela empresa se preocupa com algo maior do que seu próprio lucro." (FAE BUSINESS, 2004, p.10)

Ainda na mesma linha de opinião o presidente do O Boticário, Miguel Krigsner:

\begin{abstract}
Maior retenção de talentos, maior envolvimento e comprometimento dos colaboradores, credibilidade de marca, maior chance de fidelizar o consumidor, reconhecimento da comunidade em que está inserida, valorização de capital para as empresas que têm ações em bolsa etc. E o mais importante de tudo: a satisfação em ajudar a promover o bem comum. (FAE BUSINESS, 2004, p.10)
\end{abstract}

Uma imagem positiva pode gerar vitórias posteriormente. Já não basta somente ter o melhor preço. Há grande demanda por produtos com valor mais alto, mas com boa imagem, compatível com princípios éticos, morais, sustentáveis e democráticos. Pensando nestes resultados é que as empresas investem.

\title{
2 DO VOLUNTARIADO
}

Na definição da ONU (Organização das Nações Unidas): citada por Costa et. al. (2001, p.53) "o voluntário é o jovem ou adulto que, por interesse pessoal e espírito cívico, dedica parte de seu tempo, sem remuneração alguma, a atividades voltadas para o bem-estar social".

Dohme (2001) define o trabalho voluntário como aquele que não recebe qualquer contrapartida financeira pelo exercício de sua função. $\mathrm{O}$ voluntário, antes de qualquer coisa é um profissional, e cidadão comprometido que doa parte do seu tempo livre no exercício de atividades que beneficiem a sociedade onde se encontra e se caracteriza por valores como: "solidariedade, participação, cooperação, complementaridade, gratuidade, responsabilidade e convergência".

$\mathrm{O}$ voluntariado pode ser visto como meio pelo qual se exerce a responsabilidade social e também como solidariedade com o próximo através de auxílio em questões de interesse geral da sociedade e é exercido por 
meio de atividades ou projetos promovidos por instituições públicas ou privadas.

O trabalho voluntário é uma das ferramentas da responsabilidade social. Segundo dados da ONU no Brasil havia aproximadamente $42 \mathrm{mi}-$ lhões de voluntários no país no ano de 2002, atualmente avalia-se que este número esteja três vezes maior.

Para o fundador Associação de Apoio à Criança com Câncer (AACC):

\begin{abstract}
Ser voluntário é ter o desejo de aplicar seus conhecimentos e habilidades especiais; participar de atividades que são importantes para a comunidade; ter um grande desejo de ajudar os outros; obter reconhecimento; sentir-se útil e necessário; ter interesse em aprender novas habilidades e participar de atividades agradáveis; corresponder à ajuda recebida anteriormente; aproveitar o tempo livre; diminuir a solidão e sentir que a própria vida tem um objetivo, um significado e alguma importância.
\end{abstract}

Perez e Junqueira (2002) levantam como benefícios do trabalho voluntário os seguintes:

\begin{abstract}
É bom para a pessoa que se voluntária pelo sentimento de ser útil pela consciência de estar fazendo a sua parte, por ser reconhecida como parte de uma comunidade, por viver experiência e emoções que a vida rotineira nunca lhe proporcionaria e muitos outros motivos. É bom para a comunidade ou para a pessoa beneficiada pela ação voluntária, por que se sentem reconhecidas, respeitadas, porque recebem apoio e instrumentos para que reorientem suas vidas e revitalizem suas comunidades, porque são importantes pelo seu testemunho de luta por um destino melhor. $\mathrm{O}$ voluntariado é bom também para a sociedade, pois introduz nas relações práticas de enorme valor para a democracia: solidariedade, trabalho em equipe, respeito pela diversidade, comprometimento com causas, ações em parcerias etc. (PEREZ e JUNQUEIRA, 2002, p.22).
\end{abstract}

Costa et. al. (2001) afirmam que a importância do trabalho voluntário se dá por ser este, instrumento para otimizar a qualidade de vida, entre outros benefícios para a coletividade.

$O$ voluntariado pode ser visualizado em duas esferas: a empresarial e a social. Na empresarial, Costa et. al. dá a seguinte definição: "o conjunto de ações realizadas por empresas para incentivar, apoiar e suportar o envolvimento de seus funcionários em atividades voluntárias na comunidade." (COSTA et. al., 2001, p.24) 
Ou seja, ele é um elemento inerente nos programas de responsabilidade social.

Na esfera social, Perez e Junqueira (2002, p.146) afirmam a respeito do trabalho voluntário: "ganha relevância como uma forma de mobilizar diferentes segmentos sociais para contribuir na construção de uma sociedade mais justa e equânime." (PEREZ E JUNQUEIRA 2002, p.146)

Tanto em uma como na outra esfera merece destaque que o voluntariado envolve "pessoas comprometidas com o bem coletivo, onde a iniciativa individual não privilegia interesses individuais, mas o coletivo", de acordo com Perez e Junqueira (2002, p.139).

Costa et. al. (2001, p.53) apregoa que "ser voluntário é ajudar, é socorrer as pessoas e as populações em situação de risco. Mas é também ação efetiva para transformação social."

Costa et. al. (2001) argumentam que os voluntários devem ser agentes de transformação. No mesmo sentido, Perez e Junqueira (2002, p.146) afirmam que "a articulação de voluntários, organizações públicas e agentes econômicos, preocupados com a realidade social, constitui um meio para tornar mais eficaz a gestão das políticas sociais."

Assim, o voluntário é tido como o pivô para a transformação social, ou seja, peça fundamental para o exercício e sucesso de ações sociais propostas pelas empresas na sociedade como um todo.

Acerca do assunto Perez e Junqueira (2002) afirmam:

A ação voluntária na perspectiva de transformação social e como garantia de cidadania envolve duplo horizonte. Ação Social Vinculada - Isto é, realizada com conhecimentos e parceria com políticas públicas, de modo a qualificá-las, complementá-las, exercer o controle social dos procedimentos, do orçamento-social de cada área. Ação em defesa da ética pública - valorização do meio ambiente, do espaço público, da rua, das praças, que interfira nos padrões de qualidade de vida para todos em uma cidade.

Defesa do patrimônio público e ambiental. Ação de cidadania - realizada no âmbito da valorização da democracia, principalmente junto às instituições, como, por exemplo, o Voto Consciente com o Legislativo; o Orçamento Participativo com o Executivo; as ações contra a violência e a criminalidade; ações contra a corrupção em órgãos públicos e no Legislativo. Ação civilizatória - a perspectiva de avanço civilizatório supõe trabalhar diversos valores como ética, estética, felicidade. $\mathrm{O}$ voluntariado é parte do capital social de uma sociedade. (PEREZ e JUNQUEIRA, 2002, p.60-61-62).

Perez e Junqueira (2002) ainda observam que: 
O voluntariado é uma saída. É a nossa melhor oportunidade de envolver o cidadão, as comunidades, as associações de classe, todos os setores enfim da sociedade, no desenho e na construção de um futuro melhor. [...] Esta vontade de agir concretiza-se, por decisão de foro íntimo, em doação de tempo, qualificação profissional e talentos para o fortalecimento de pessoas, movimentos e organizações sociais, projetos comunitários, esportivos, recreativos, educacionais, de saúde, de defesa de direitos, de proteção ao meio ambiente, etc. [...] Finalmente acontece a mudança na sociedade (que se contamina com os valores das ações voluntárias e tem oportunidade de se rever, de se repactuar). (PEREZ e JUNQUEIRA, 2002, p.66).

Fica claro, o quão importante é a existência do voluntariado. É possível até dizer que o voluntariado está para a responsabilidade social, como o colaborador está para a empresa.

\section{CONSIDERAÇÕES FINAIS}

Conforme exposto, há um ponto de partida para apreciações mais profundas sobre o tema da responsabilidade social, suas esferas de atuação e objetivos.

O que se nota é que o tema permite uma análise múltipla. Ferramenta de Marketing ou estratégia empreendedora tal prática não parece um modismo passageiro e sim uma prática que se vinculou à administração e objetivos corporativos permanentemente, ao passo que a população já espera essa postura das empresas, principalmente em relação ao meio ambiente e à educação.

Inerente ao tema avista-se o voluntariado, que na esfera empresarial ainda é uma questão muito recente, mas com muito a desenvolver uma vez que as grandes empresas vêm exercitando um papel relevante através dos projetos sociais junto ao governo. Figura de importante destaque o voluntário além de ferramenta essencial dentro da responsabilidade social ainda ganha ao espalhar e trocar valores morais como ética e solidariedade, já que mais se aprende com o exemplo.

Outro fator notável é o papel da mídia, principalmente a televisiva, na contribuição para a conscientização da sociedade quanto à responsabilidade social, o desenvolvimento de projetos sociais por parte do setor privado, bem como a conscientização do consumidor, através da compra consciente e também de cobrar e acompanhar o desenvolvimento de referida postura. 
Apesar de não ser obrigação primordial da iniciativa privada, mas sim do Estado, o desenvolvimento de atividades sociais e de políticas públicas e até mesmo ambientais, é uma tendência que surgiu para ficar e cada vez mais se aperfeiçoar e crescer. As empresas notaram que a responsabilidade social é uma estratégia positiva e que assim podem unir o útil ao agradável: fazer seu papel social, diminuir gastos e atingir sucesso financeiro a longo prazo.

Por fim, é importante lembrar que as ações sociais são dignas de valorização da empresa, sejam elas de qualquer natureza, pois as empresas devem exercer tais atividades da maneira mais correta possível, no que faz relação com leis, regras e valores morais, vez que o consumidor tem se tornado cada vez mais exigente.

\section{REFERÊNCIAS}

BRASIL. Decreto 7052. Disponível em: www.planalto.gov.br/ccivil_03/_Ato20072010/2009/Decreto/D7052.htm Acesso em: 21. ago. 2018.

CARROL, A.B., 1979. A Three dimensional conceptual model of corporate performance. Academy of Managemet Review (pre-1986); Oct 1979; 4, 000004; ABI/INFORM

COSTA, Antônio Carlos Gomes da et al. Seminário legislativo voluntariado: você faz a diferença: documento final. Belo Horizonte: Assembléia Legislativa do Estado de Minas Gerais, 2001. 72p.

DOHME, Vânia D'Angelo. Voluntariado e equipes produtivas: como liderar ou fazer parte de uma delas. São Paulo: Mackenzie, 2001. 210p

INSTITUTO ETHOS. Disponível em: www.ethos.org.br Acesso em: 18 jun. 2018.

MOREIRA, Ana Lúcia; MATTIUZ, Carlos Antônio; SOUZA, Sônia Custódio de. Voluntariado empresarial: uma ferramenta para o desenvolvimento de competências humanas. Nova Lima: Fundação Dom Cabral, 2004.

PEREZ, Clotilde; JUNQUEIRA, Luciano A. Prates. Voluntariado e a gestão das políticas sociais. São Paulo: Futura, 2002. 391p.

REVISTA FAAP. Disponível em: www.faap.br/revista_faap/revista_facom/facom_17/silvio.pdf. Acesso: 15 jun. 2018.

PORTAL TRABALHO VOLUNTÁRIO. Artigos voluntariado. Disponível em: www.espirito.org.br/portal/artigos/diversos/assistencia/o-trabalho-voluntario.html. Acesso: 12. jul. 2018. 